\title{
JOGOS EM SALA DE AULA: FERRAMENTA QUE POTENCIALIZA A APRENDIZAGEM OU APE NAS UMA PROPOSTA LÚDICA?
}

\author{
CLASS GAMES: TOLL THAT POTENCIALISES THE LEARNING OR \\ JUST ON PLAYFUL PURPOSE?
}

\author{
${ }^{1}$ Silvia Kelly Torres da Cunha, ${ }^{2}$ Karine Nayara Faria do Valle, ${ }^{3}$ Everton Beghini Viriato Lopes \\ Centro Universitário de Belo Horizonte (UNI-BH) \\ ${ }^{1}$ silviaktc@yahoo.com.br ; ${ }^{2}$ karine-valle@ hotmail.com; ${ }^{3}$ evertonbeghini@uol.com.br
}

Orientadora: Profa. Mestre Luciana Maria Tenuta de Freitas (UNI-BH)

lutenuta@gmail.com

\begin{abstract}
RE SUM O
Este trabalho apresenta os resultados de uma pesquisa realizada a partir de entrevistas para tentar identificar se os professores utilizam os jogos nas aulas de Matemática da forma como está proposto nos atuais documentos e na literatura da área de Educação Matemática. Procuramos também identificar se as falhas encontradas são decorrentes de sua formação. Participaram da pesquisa três professoras de escolas publicas de Belo Horizonte. A coleta dos dados foi feita por meio de uma entrevista cujo objetivo era saber se os professores têm clareza quanto ao significado do jogo no ensino de Matemática e se conhecem as propostas dos documentos oficiais sobre essa temática. Os resultados mostraram que o uso dos jogos como metodologia de ensino não se dá de forma simples e que para alcançar os objetivos desejados, é necessário que os professores estejam constantemente refletindo sobre como e porquê utilizar os jogos no ensino de Matemática, se dispondo a desenvolver estratégias que favoreçam o desenvolvimento de hábitos de investigação nos alunos.
\end{abstract}

Palavras-chave: Educação Matemática. Jogos. Formação de professores.

\begin{abstract}
These work, presents the results of an enterview reseach to try identify if the teachers utilizes games in the math class how is proposed on actual documents and the literary area of Mathematics Education. Seaching idetify if the failures found are from your formation. Three teachers of public schools of Belo Horizonte participated on this research. The data collect was dono by enterviews whose
\end{abstract}

goal was to know if the teachers has distinctness about the means of the game on math teach and if they know the purposes of official documents about this case. The results shows that the use of games like teach methodology is not simple to reach the desire objectives, it's necessary that the teachers be thinking constantly how and why apply games on math teach, developing new estrategy that favor the habits of investigation students Keywords Mathematics Education.
Games.Teacher Training.

\section{INTRODUÇÃO}

Este trabalho teve sua motivação em nossa caminhada enquanto alunos de graduação. No decorrer do curso de graduação em Matemática, presenciamos por diversas vezes muitas discussões sobre a utilização de metodologias diferenciadas no ensino da matemática e fomos motivados por nossos professores a introduzir o jogo como meio de desenvolver habilidades matemáticas nos alunos. Os jogos são considerados como um recurso pedagógico que se bem utilizado pode contribuir e muito para que o aluno desenvolva competências matemáticas. 
(...) a atividade de jogar, se bem orientada, tem papel importante no desenvolvimento das habilidades de raciocínio como organização, atenção e concentração, tão necessárias para o aprendizado, e especial da Matemática, e para a resolução de problemas em geral. (BORIN, 1995, p. 8)

Sendo assim, o que despertou nossa atenção foi o confronto entre a parte teórica e a prática de sala de aula ao trabalharmos com jogos. Foi assim que surgiu nossa pesquisa. Existe uma grande motivação em trabalhar com jogos, mas percebemos que na maioria das vezes não há preocupação por parte dos professores de realmente ensinarem matemática a partir de conhecimentos prévios dos alunos através dessa metodologia e sim o seu uso apenas com o objetivo de entreter seus alunos. Além disso, outro fator que nos intriga, é que apesar de durante todo o tempo em que estivemos na faculdade os jogos não foram escolhidos como prática pedagógica. Dessa forma, como saberemos utilizá-los de modo a contribuir no processo de ensino e aprendizagem se nós não experimentamos esse tipo de trabalho no decorrer de nossa graduação?

Os jogos são considerados atividades que envolvem e motivam os alunos. Além de proporem problemas de forma mais interessante, possibilitam a criação de estratégias e ainda, por se tratar de jogo, não marca tanto o educando quando este percebe seu erro.
(...) os jogos constituem uma forma interessante de propor problemas, pois permite que sejam apresentados de modo atrativo e favorecem a criatividade na elaboração de estratégias de resolução em busca de soluções. Propiciam a simulação de situações problema que exijam soluções vivas e imediatas, o que estimula o planejamento das ações; possibilitam a criação de uma atitude positiva perante os erros, uma vez que as situações sucedem-se rapidamente e podem ser corrigidas de forma natural, no decorrer da ação, sem deixar marcas negativas. (BRASIL, 1998, p. 46)

No entanto, na maioria das vezes este recurso didático é utilizado apenas como meio de interação e descontração. Muitos professores buscam uma maneira de prender a atenção dos alunos e até mesmo fazer com que sua aula seja agradável, prazerosa e acabam deixando de lado a possibilidade de se explorar o pensamento matemático que os jogos oferecem. Este é o tema de nossa pesquisa: o professor tem clareza quanto aos objetivos de se trabalhar com jogos em sala de aula de modo a potencializar o ensino da Matemática? Ele foi preparado para isso?

Os jogos são mais uma metodologia de ensino a ser utilizada de acordo com a necessidade, ocasião e objetivo, mas será que são usados de modo a ajudar o aluno a compreender a Matemática?

\section{OBJETIVOS}

Nossa proposta de pesquisa tem como objetivo analisar se os professores de 
matemática utilizam os jogos no processo de ensino-aprendizagem conforme propõem os atuais documentos e bibliografias da área. Pretendemos identificar também se os possíveis equívocos encontrados na utilização dos jogos em suas aulas são decorrentes de sua formação.

Para isso analisamos se os professores têm clareza de como podem ser utilizados os jogos para potencializar o ensino de Matemática.

Para fazer essa análise buscamos identificar se o professor graduado tem clareza quanto:

B Ao significado do jogo no ensino de Matemática.

ß Às atuais propostas dos documentos oficiais, os Parâmetros Curriculares Nacionais (PCN), ou outras bibliografias que apontam o uso dos jogos como prática pedagógica.

Analisamos então se os jogos são usados de modo eficaz podendo "descentralizar, criar a possibilidade do desenvolvimento da linguagem, criatividade, raciocínio dedutivo e argumentação" conforme afirma Borin (1998).

\section{J USTIFICATIVA}

Nos últimos tempos temos visto falar de novas práticas no ensino da Matemática com o intuito de promover melhor interação dos alunos, maior desenvolvimento do pensamento matemático destes, além de desmistificar a idéia de que a Matemática é um "bicho-desete-cabeças", tornando-a mais agradável e relacionada ao cotidiano do aluno.

Essas metodologias inovadoras são muito discutidas e trazem estratégias envolventes tais como jogos, teatro, computadores, entre outros. Realmente essas metodologias são muito aclamadas e de certo modo até empolgantes, mas será que são realmente usadas de modo que ajudem o aluno a atingir verdadeiramente o objetivo proposto com a atividade?

Sendo assim, optamos por escolher os jogos como trabalho de pesquisa no sentido de observar e analisar quais os rumos que estão sendo tomados para a utilização de novas práticas pedagógicas.

A experiência que tivemos até o momento com jogos em sala de aula foi apenas teórica e queremos saber se realmente funciona. E como aprender uma nova metodologia sem experimentá-la? Apenas a nossa própria experiência educacional será suficiente para nos ajudar a trabalhar com um novo jeito de ensinar Matemática? O que se percebe, é que por ser a Matemática conhecida como uma 
matéria maçante, cansativa, entediante e muitas vezes chata, muitos professores procuram a qualquer custo chamar a atenção de seus alunos. Será que os jogos quando utilizados pelos professores de Matemática terão se constituído apenas como uma forma de entreter os alunos?

Consoante ao que já foi acima relatado, acreditamos que este projeto de pesquisa tem importância social, uma vez que tentamos verificar se através dos jogos é possível contribuir para a formação de um sujeito autônomo capaz de pensar, articular, responder a questões, ter seu próprio ponto vista.

No momento em que vários professores e diretores sentem-se divididos entre o desejo de mudar e a estatística trazida pelos testes de aquisição de conhecimentos, não podemos nos furtar de lembrar o papel da autonomia em outros movimentos de reforma. (KAMII, 1995, p. 14)

Esse projeto possui ainda um caráter formativo, visto que os jogos têm sido apontados como grande incentivo para tentar diminuir a rejeição dos alunos a se envolverem em situações problema.

Dentro da situação de jogo, onde é impossível uma atitude passiva e a motivação é grande, notamos que, ao mesmo tempo em que estes alunos falam matemática, apresentam também um melhor desempenho e atitudes mais positivas frente aos processos de aprendizagem. (BORIN, 1998, p. 9)

Para tanto buscamos mostrar alguns referenciais teóricos sobre como e porque utilizar jogos em sala de aula.
Ainda podemos considerar as possibilidades de tentar recuperar a vontade de aprender dos alunos e o possível desenvolvimento de atitudes favoráveis à aprendizagem da Matemática por meio dos jogos.

(...) um determinado jogo é bom se permite várias explorações no sentido de promover o exercício do pensamento crítico daqueles que jogam. Caso contrário, ele se caracteriza como um passatempo e pode ser deixado para os momentos de lazer, quando os aspectos lúdicos e sociais são importantes. (BORIN, 1998, p. 18)

Dito isto, acreditamos ser o estudo dos jogos como metodologia de ensino de Matemática um assunto de extrema importância na formação de professores, pois devemos analisar e compreender como trabalhar com essa nova tendência sem abrir mão dos conhecimentos científicos que devem ser apropriados neste tipo de proposta pelos alunos. Deixar de encarar os jogos apenas como brincadeira e utilizar os próprios jogos ou qualquer outra metodologia como forma de levar os alunos a fazer Matemática só depende de nós: os professores.

\section{REVISÃO DE LITERATURA}

De acordo com a proposta dos PCN (1998), não existe um único caminho a ser seguido para se ensinar melhor em qualquer disciplina e o importante é que o professor conheça as diversas práticas que podem ser adotadas para potencializar o 
ensino e possa então construir a sua.

Dentre estas práticas, destaca-se o trabalho com jogos para potencializar o processo de ensino e de aprendizagem.

Kamii(1995), defende que o jogo é um instrumento que pode auxiliar os alunos a desenvolver a autonomia, o senso crítico e confiança. Ainda segundo esta autora, os jogos desenvolvem a capacidade de criar estratégias sendo mais interessantes do que apenas resolver listas de exercícios.

Nos PCN (1998), o jogo é considerado uma prática que desenvolve princípios psicológicos, é uma atividade que não é vista como obrigação, tornando a aprendizagem mais prazerosa, sem obrigação para as crianças e ainda pode ser visto como uma atividade funcional que dá significação à aprendizagem.

O jogo é uma atividade natural no desenvolvimento dos processos psicológicos básicos, supõe um "fazer sem obrigação imposta" embora demande exigências, normas e controle.

(...) Para crianças pequenas, os jogos são as ações que elas repetem sistematicamente, mas que possuem um sentido funcional (jogos de exercícios), isto é, são fontes de significado, e portanto possibilitam a compreensão, geram satisfação, formam hábitos que se estruturam num sistema. (BRASIL, 1998, p. 42)

Estudos sobre o lúdico e os jogos na aprendizagem escolar (Macedo; Petty; Passos, 2005), apontam que os jogos são um aprimoramento do brincar, é um brincar organizado:

(...) O jogar é um dos sucedâneos mais importantes do brincar. O jogar é um brincar com contexto de regras e com um objetivo predefinido. [...] $\mathrm{O}$ brincar é um jogar com idéias, sentimentos, pessoas, situações e objetos em que as regulações e objetivos não estão necessariamente predeterminados. No jogo ganha-se ou perde-se.[...] O jogar é uma brincadeira organizada, convencional, com papéis e posições demarcadas. (MACEDO; PETTY; PASSOS, 2005, p.14)

A idéia de jogar é muito mais do que simples diversão. Esses autores acreditam no lúdico no ensino de Matemática, ou de outra disciplina, como estimulador do desenvolvimento do raciocínio lógico, fazendo dele uma forma de observar por diversos olhares as possibilidades de expressão. Ainda segundo Macedo; Petty; Passos (2005), se soubermos observar a presença do lúdico nas escolas, poderemos compreender resistências e limitações que acabam por tornar a escola sem significação para as crianças.

Nas salas de aula de hoje, temos muitos alunos desinteressados em aprender e a partir da utilização de jogos o professor deve buscar instigá-los na busca pelo conhecimento, tentar diminuir os bloqueios e fazer com que os alunos possam desenvolver suas próprias capacidades e potencialidades na aprendizagem de Matemática, fazendo-os comunicar-se através dos jogos. (BORIN, 1998; KAMII,1995; $\quad$ MAECEDO; PETTY; PASSOS 2005) 
Borin (1998) recomenda que para alcançarmos este objetivo de comunicar, aprender e ensinar através dos jogos, os professores devem estar atentos para não transformar tudo em jogo, sempre se questionar por que e para que usá-lo e enxergá-lo como uma das muitas estratégias no ensino e aprendizagem da Matemática.

(...) as condições para aprender não se encontram no jogo, assim como não se encontram em nenhum material que possamos utilizar.A aprendizagem decorre das reflexões que o aluno elabora e dos significados que ela estabelece a partir do que já conhece. Os jogos e os materiais didáticos são bons na medida em que permitam a reflexão e a construção de múltiplos significados para cada idéias a ser aprendida. O sucesso de uma metodologia, ou do uso de um material, está na confiança e no conhecimento que o professor tem sobre o potencial dos mesmos e na disposição de aprender junto com seus alunos. (BORIN, 2005, p.80).

\subsection{JOGOS E RESOLUÇÃO DE PROBLEMAS}

Para Skovsmose (2000), “um cenário para investigação é aquele que convida os alunos a formularem questões e buscarem explicações". Para que isto ocorra o autor recomenda que deve ser feito um convite aos alunos a participarem do processo de exploração e explicações de situações problemas. E este cenário de investigação somente existe se os alunos aceitam o convite.
Conforme afirmam Macedo et. al (2005), qualquer jogo supõe uma pergunta inicial: vamos jogar? Podendo a pessoa dizer sim ou não ao convite. Ao responder sim, a criança poderá ser levada a despertar em si o desejo de aprender e o prazer de realizar as atividades escolares promovendo o aprendizado.

Uma forma interessante de promover
a aprendizagem ou avaliar é a
situação-problema. Contextos de
projetos ou jogos são prenhes de
situações-problemas, as quais
consistem em colocar um obstáculo
cuja superação exige do sujeito
alguma aprendizagem ou esforço.
(MACEDO; PETTY; PASSOS,
2005, p. 18).

$\mathrm{O}$ jogo nesse sentido passa a ter um sentido de investigação e curiosidade fazendo com que o aluno reflita enquanto faz suas jogadas e a partir daí consiga desenvolver seu raciocínio. $O$ jogo se configura assim como um cenário que dará suporte para a investigação.

Para Borin (1998), “algumas técnicas de resolução de problemas aparecem naturalmente durante os jogos". Dentre essas técnicas podemos destacar a redução a um problema mais simples, tentativa e erro, resolução de um problema de trás para frente ou mesmo analogia a problemas semelhantes.

Os jogos como formas de resolução de problemas devem construir um ambiente em que haja reflexão, levando o aluno construir seus significados de modo a tornar a matemática mais criativa, 
fazendo as coisas de um jeito melhor, mais saudável e com mais sentido. (MACEDO; PETTY; PASSOS, 2005; BORIN, 1998).

Para Skovsmose (2000), um cenário para investigação deverá levar o aluno a reconhecer suas próprias capacidades matemáticas e à consciência da forma pela qual a Matemática opera em certas estruturas lógicas, buscando através dessa metodologia, um ambiente diferente de aprendizagem de modo que tenha uma dimensão crítica.

A metodologia de resolução de problemas para o trabalho com jogos é a mais adequada segundo Borin (1998) por ser essencial que os alunos trabalhem em grupo. Este tipo de organização dos alunos pode favorecer a obtenção de melhores resultados além de fazer com que os alunos possam desenvolver uma postura crítica em qualquer situação que exija uma resposta. Cada pergunta feita em um jogo pode desencadear uma série de outras que fazem com que os alunos pensem, conjecturem e cheguem a conclusões matemáticas.

\section{METODOLOGIA}

Nesta pesquisa, optamos por fazer a coleta de dados por meio de entrevistas com professores do ensino médio e fundamental de escolas públicas. Inicialmente a escolha por fazer a coleta de dados por meio de entrevistas deu-se por pensarmos, naquele momento, que haveria da nossa parte uma maior facilidade de acesso aos professores pesquisados do que realmente houve.

Para obtenção dos dados aplicamos um questionário para três professoras da rede pública de ensino de entrevistas com dez perguntas básicas sobre o trabalho com jogos: como e por que utilizá-los, com que objetivo, com que frequiência e de onde as atividades eram retiradas. Este questionário permitiu unificar as entrevistas de modo a criar as categorias de análise.

Durante as entrevista tentamos perceber como os professores trabalhavam com jogos e se possuíam dificuldades ou facilidades na utilização dessa prática pedagógica. Além disso, procuramos saber se os professores pesquisados conheciam os documentos oficiais a fim de tentar entender se existe ou não a dificuldade de se fazer Matemática através do lúdico.

\section{TRATAMENTO DE DADOS}

A análise dos dados dessa pesquisa foi feita considerando as três professoras entrevistadas. São elas: Catilene, Maria e Lara. Todos os nomes são fictícios para que possamos preservar a identidade das professoras.

Realizamos um encontro para cada entrevista exceto no caso da professora Lara que respondeu apenas ao questionário 
pela internet, não havendo contato pessoal com esta professora.

\subsection{AS PROFESSORAS ENVOLVIDAS Catilene}

Catilene tem 23 anos, é solteira e trabalha em uma escola pública da rede estadual de ensino. Formou-se no Centro Universitário de Belo Horizonte em 2006. Aparentemente gosta do que faz e mostrou-se disponível e acessível para a realização da entrevista. Cursou a educação básica em escola pública e no momento está fazendo especialização em Educação Matemática. Acredita que por trabalhar em um laboratório de ensino de matemática possui uma bagagem grande no trabalho com essa prática: "Quem está ali em contato com o laboratório tem uma bagagem grande em relação a jogos", diz Catilene.

\section{M aria}

Maria tem 26 anos, é solteira trabalha com ensino fundamental numa rede particular de ensino e com ensino médio de uma escola pública. Cursou a educação básica em escola pública e graduou-se em Matemática Licenciatura Plena no Centro Universitário de Belo Horizonte em 2005. Hoje faz especialização em Educação Matemática nessa mesma instituição. Mostra ter paixão pelo que faz. Durante a entrevista demonstrou grande preocupação em como \begin{tabular}{l|l|l} 
e-xacta & Belo Horizonte & ISSN 1984-3151
\end{tabular} trabalhar com jogos com seus alunos no intuito de não ser apenas um modo de entretê-los, mas admite não ter maturidade suficiente para criar jogos com o intuito de potencializar o ensino da Matemática. Maria esteve bastante disponível e interessada durante a entrevista.

(...) inicialmente para mim o jogo era só para ficar bonitinho e atrativo. [...] Acredito que o jogo tem que ser atrativo sim, mas depende da forma que você trabalha o jogo você consegue mais matemática. (MARIA).

\section{Lara}

Lara tem 27 anos, é casada e trabalha com ensino médio e fundamental da rede pública de ensino. A professora cursou a educação básica em escola pública e graduou-se no primeiro semestre de 2008 pelo Centro Universitário de Belo Horizonte. Pretende fazer especialização em Educação Matemática no próximo ano.

Contou que sempre quis ser professora, desde pequena, e agora faz o que gosta. Devido à incompatibilidade de horários, a entrevista de Lara foi realizada pela internet e houve vários contatos por telefone com essa professora. Apesar de acreditar que o trabalho com metodologias diferenciadas, como os jogos, possa potencializar o ensino da Matemática, acredita não saber trabalhar corretamente com os jogos em sala de aula visto que durante toda a sua vida escolar, inclusive na graduação, baseou-se no tradicionalismo: "Como não tive a \begin{tabular}{l|l} 
www.unibh.br/revistas/exacta & v. 2, n. 3, dez.2009
\end{tabular} 
oportunidade de trabalhar com jogos durante a graduação não me sinto preparada para fazer bem feito. Acho que estou acostumada com as aulas tradicionais", conta Lara.

Contudo, se diz satisfeita com seu trabalho e gostar muito de ensinar.

\subsection{ANÁLISE DAS ENTREVISTAS}

Nosso trabalho contemplou entrevistas com as três professoras supracitadas no intuito de analisar como essas professoras percebiam o jogo nas aulas de Matemática, o conhecimento e a utilização dos jogos como forma de potencializar o ensino da Matemática.

Nas entrevistas pudemos observar que todas as professoras consideram importante o uso dos jogos em sala de aula e os utilizam.

A professora Catilene justifica a importância do uso de jogos em sala de aula por ser uma ferramenta motivadora: "O jogo é uma atividade motivadora porque se utilizado na hora certa, vai ser muito eficaz".

Já a professora Maria acredita que a importância da utilização dos jogos se dá pelo seu caráter lúdico e por este motivo o aluno se sente livre para colocar suas idéias e criar estratégias de resolução:

(...) dependendo da forma que se trabalha o jogo você consegue mais matemática, porque o aluno fica mais livre para colocar suas idéias.
Quando você pega um jogo ele tem uma idéia de competição, então ele tem uma empolgação maior. $\mathrm{O}$ aluno consegue criar estratégias de resolução. (MARIA)

Quanto à Lara, esta acredita que o uso de jogos em sala de aula é uma forma de praticar o raciocínio lógico fugindo de repetições:

O uso de jogos em sala de aula é válido porque faz com que o aluno possa ter e poder criar outras formas de raciocínio, não ficando com aquilo que se diz de repetições e sim praticar o raciocínio lógico. (LARA)

A partir dos dados coletados pudemos perceber que todas as professoras percebem a importância da utilização de jogos em sala de aula e como estes podem de algum modo contribuir para a potencialização do ensino da Matemática. Conforme afirma Kamii (1995), os jogos são instrumentos que fornecem oportunidades de criar estratégias e tornam-se muito mais estimulantes do que apenas completar folhas de exercícios. Além disso, segundo alerta Borin (1998), através dos jogos o aluno pode ser um "elemento ativo do processo de aprendizagem, vivenciando a construção do seu saber e deixando de ser um ouvinte passivo de nossas [dos professores] explicações". Para a autora, os jogos são também as atividades que mais envolvem e motivam os alunos.

No entanto, os dados também evidenciaram que apesar das professoras demonstrarem consciência quanto aos 
objetivos de se utilizar os jogos na prática escolar, todas afirmaram já terem utilizado essa prática sem o objetivo de fazer Matemática através deles. Usaram os jogos sem um aspecto de investigação que levasse os alunos a conseguir criar suas próprias conclusões e demonstrações. Apenas os levaram a jogar por jogar. Afirmaram que os jogos foram apenas utilizados para acalmar a turma ou para fixar algum conteúdo.

Já aconteceu de eu levar os alunos para o pátio com jogos só para distrair os mesmos. (CATILENE)

São [os jogos, propostos em $\mathrm{CD}$ que a professora possui] uma forma diferente de fazer exercícios, não são investigativos. Não vou dizer que não utilizei, já usei sim, mas não tem esse potencial investigativo. (MARIA)

Muitas vezes uso os jogos para fazer com que os alunos fiquem quietos. Nem sempre tenho um objetivo matemático com o jogo. (LARA)

Essas afirmações conflitam com as propostas dos Parâmetros

Curriculares Nacionais (1998):

Os jogos podem
contribuir para um
trabalho de formação
de atividades -
enfrentar desafios,
lançar-se à busca de
soluções,
desenvolvimento da
critica, da intuição, da
criação de estratégias
[...] necessária para a
aprendizagem da
Matemática. (BRASIL,
1998, p. 47)

Os depoimentos ainda vão contra as propostas de Borin (1998), que aponta o jogo como forma de desenvolver nos alunos o hábito de pensar sobre um problema sem esperar respostas prontas.

O jogo desenvolveu nos alunos o hábito de explorar as possibilidades ao acaso, sem a preocupação de achar uma fórmula pronta, sem uma técnica específica, exatamente como se inicia a pesquisa em matemática. (BORIN, 1998, p. 5)

A autora alerta ainda que os jogos não devam ser vistos apenas como diversão para que se possa conseguir desenvolver, por exemplo, o raciocínio lógico que é uma grande meta do ensino da Matemática. Borin (1998) aponta que “(...) é necessário que os jogos sejam escolhidos e trabalhados com o intuito de fazer o aluno ultrapassar a fase da mera tentativa e erro, ou jogar pela diversão apenas".

Um dos motivos para que as professora adotem tal postura acerca do trabalho com jogos, pode ser a pouca experiência com o trabalho dessa metodologia enquanto estudantes de graduação do curso de Matemática, conforme afirmam as próprias professoras. As entrevistas evidenciam que o fato de não terem tido a oportunidade de trabalhar com jogos enquanto estudantes foi significativo uma vez que dentre as três entrevistadas, Maria e Lara afirmaram que não tiveram oportunidade de experimentar o trabalho com jogos antes da prática de sala de aula.

O fato de não ter tido oportunidade de praticar os jogos quando era universitária, prejudicou de forma significativa, pois tive uma formação 
tradicional, e então, você acaba acreditando que o outro também aprenderá desta forma. [...] Tive a parte teórica, mas faltou a parte prática. (MARIA)

Não tive oportunidade de trabalhar com jogos na faculdade, mas não condeno tal fato, porque acho que os professores antigamente não tinham suporte para esse tipo de aula. Deveriam mas não tinham. (LARA)

Ainda foi possível destacar, após a análise das entrevistas, que durante a graduação houve a introdução da parte teórica sobre o objetivo da utilização dos jogos. Mas, segundo as professoras, o contato com textos oficiais e outras bibliografias sobre jogos durante a graduação não foi suficiente para a aplicação dessa prática em sala de aula. Elas acreditam que a própria prática é que faz pensar qual o melhor jogo, porque e como utilizá-lo.

Para Maria, mesmo tendo feito a leitura dos Parâmetros Curriculares Nacionais no que diz respeito à utilização de jogos nas aulas de Matemática, esse objetivo não ficou muito claro. Somente na Pós-graduação a professora se sentia mais madura para usar esse tipo de metodologia:

$\mathrm{Na}$ graduação a gente teve contato sim [PCN's e outras bibliografias sobre jogos], porém você não percebe isso tão claramente. $\mathrm{Na}$ prática e na pós essas idéias foram mais bem discutidas, pois minha maturidade de acolher as informações era diferente, não é específico do curso. Saí da graduação conceituando jogo apenas como lúdico. (MARIA)

Catilene por sua vez, acredita saber o básico sobre as propostas dos documentos oficiais mas não os utilizou até hoje durante a prática de sala de aula:

Tenho sim [o conhecimento] básico sobre os PCN's. O que eu aprendi na faculdade.

Não me aconteceu isto [recorrer ao PCN]! Pode até ser falha minha [...] mas até então o conhecimento que eu tenho é realmente o que aprendi na faculdade. (CATILENE)

Já Lara, acredita que é a prática que auxilia no pensamento dos objetivos da utilização dos jogos:

Tenho um pouco de conhecimento [sobre os pcn's]. A prática na sala de aula é que realmente te faz pensar e analisar sobre tais jogos que deve fazer uso. (LARA)

Apesar de já terem utilizado os jogos apenas como entretenimento, sem objetivos concretos no ensino de Matemática, as professoras também os utilizaram como forma de levar o aluno a refletir e elaborar conhecimentos a partir do que já conhece. Mas, segundo elas afirmam, não são capazes de introduzir conteúdos matemáticos. As professoras têm clareza quanto aos objetivos da utilização de jogos, já que conhecem as propostas dos documentos oficiais. Mas de todo modo, elas não conseguem utilizar essa metodologia para propiciar o desenvolvimento do raciocínio investigativo introduzindo conteúdos.

(...) nunca consegui trabalhar com jogos para introduzir uma definição. Através do jogo eu consigo perceber se os alunos assimilaram o conteúdo. (MARIA)

(...) tem quer já um conhecimento [o aluno] para que o jogo funcione, tem que ter uma introdução básica para 
que ele [o aluno] entender porque você está dando aquele jogo, porque você está dentro daquele conteúdo. (CATILENE)

(...) [para escolher os jogos] eu faço uma pequena pesquisa voltada para o conteúdo que está sendo aplicado para a classe. (LARA)

O jogo assim foge da proposta de se trabalhar com esta metodologia a fim de fazer com que os alunos estejam envolvidos em cenários de investigação em que formulam questões e buscam explicações como propõe Skovsmose (2000). Ainda neste sentido, o uso de jogos em sala de aula discorda com a proposta de Borin (1998) que aponta o uso dos jogos na resolução de problemas.

(...) dentro da metodologia de resolução de Problemas, é possível explorá-los ou transformá-los [os jogos] de tal modo que um jogo estratégico possa servir para estudo de algum conteúdo e o jogo de treinamento possa envolver algumas decisões estratégicas sobre como melhorar as chances para vencer o jogo. Por isso ao tratarmos de cada jogo, iremos além de seus objetivos iniciais transformando-os em várias situações-problema que podem servir também para introdução ou aprofundamento de determinado conteúdo matemático. Na verdade um determinado jogo é bom se ele permite várias explorações no sentido de promover o exercício do pensamento crítico daqueles que jogam. (BORIN, 1998, p. 17-18)

Ao solicitarmos às professoras que descrevessem uma atividade em que utilizassem jogos, pudemos perceber dois tipos de jogos utilizados por elas: os jogos de estratégia e os jogos de treinamento.

Maria descreveu sua forma de utilizar o jogo como uma atividade que possibilitasse os seus alunos a criarem uma estratégia para conseguir encontrar divisores comuns de números. Mas, somente utilizou o jogo após já ter trabalhado o conteúdo anteriormente em sala e acredita ser necessário possuir um grande conhecimento de Matemática para conduzir esse tipo de atividade:

(...) O jogo foi utilizado depois do conteúdo trabalhado. [...] Uma estratégia utilizada pelos alunos que me chamou atenção e acabou servindo para avaliar se realmente assimilaram o conteúdo foi de que quando os alunos não conseguiam um número comum múltiplo de outros dois usavam o zero, pois é múltiplo de qualquer número. [...] o professor precisa reconhecer que pode existir uma estratégia que ele não havia pensado, porém matematicamente correta e por isso precisa ter um bom domínio do conteúdo. (MARIA)

Já Lara e Catilene desenvolveram atividades em que trabalhavam com treinamento das operações. Lara desenvolveu um jogo com dominós, cujo objetivo era que os alunos gastassem todas as suas peças tentando, através de somas, subtrações, multiplicações ou divisões chegar a determinado valor. Como nos relatou a professora, os alunos deveriam conseguir encontrar através das quatro operações, o número 30 e quem acabasse primeiro sem peças seria o vencedor. Catilene utilizou um jogo para trabalhar com números inteiros, que se encontravam em uma trilha. Cada aluno possuía pininhos e havia dois dados: um azul e outro vermelho. O dado azul representava 
os números positivos e o vermelho os negativos. Os alunos recebiam uma tabelinha para anotar as operações que estavam fazendo. Jogavam os dados e realizavam a operação de adição ou subtração. Se o resultado fosse positivo, andavam na trilha pra frente e se fosse negativo para trás.

(...) os alunos não sabem as operações fundamentais direito então posso treinar um pouco com esse jogo já que ficam mais interessados. (LARA)

(...) depois eu corrigia todas as tabelinhas para verificar como estava o nível de aprendizagem dos números inteiros [...] Como eu não achei que o conhecimento dos alunos estava bom, eu dei uma recapitulada na matéria e marquei jogo para próxima aula. (CATILENE)

Todas as professoras trabalharam com jogos, já que as atividades se enquadram nos critérios que aponta Borin (1998) de como devem ser os jogos:

O jogo deve ser para dois ou mais jogadores, ou seja, não pode ser um jogo "solitário".

O jogo deve ter regras préestabelecidas que não podem ser modificadas no decorrer da rodada

As regras devem ser formuladas de modo que ao final só haja um vencedor.

O jogo não deve ser apenas mecânico e sem significado para os alunos.

O jogo deve permitir que cada jogador possa fazer a jogada dentro das regras. A sorte deve ter um papel secundário ou mesmo em nada interferir (BORIN, 1998, p. 13-14)

No entanto, os jogos propostos

pelas entrevistadas não têm como objetivo a construção de conceitos matemáticos.

Não levam os alunos a desenvolver suas próprias capacidades e potencialidades já que não propiciam um cenário onde os alunos investiguem, criem conjecturas, experimentem, formulem hipóteses e façam generalizações. Mesmo assim, não deixam de ser jogos que propiciam o desenvolvimento do raciocínio lógico, cálculo mental, desenvolvem estimativa e que criam estratégias para realizar cálculos.

\section{CONSIDERAÇÕES FINAIS}

Neste projeto de pesquisa, pudemos analisar como os jogos são trabalhados em sala de aula por três professoras da rede pública de ensino.

Pudemos constatar que as três professoras tiveram incentivo para utilizar jogos durante os cursos de graduação e conhecem a parte teórica relativa ao assunto, ou seja, conhecem as propostas do uso de jogos nos Parâmetros Curriculares Nacionais. No entanto, todas as entrevistadas afirmaram já terem utilizado o jogo somente como entretenimento ou o fazem como treinamento das quatro operações ou como jogos de desenvolvimento de estratégia, mas não conseguem fazer este trabalho com o intuito de desenvolver o raciocínio investigativo nos alunos. Ficou claro que ao utilizar os jogos em suas aulas, as professoras entrevistadas não têm como objetivo que, a partir de situações problema, o aprendizado decorra das \begin{tabular}{l|l} 
ww.unibh.br/revistas/exacta & v. 2, n. 3, dez.2009
\end{tabular} 
próprias reflexões dos alunos a partir daquilo que já conhecem.

Acreditávamos, no inicio desta pesquisa, que encontraríamos respostas definitivas e ainda, que os equívocos encontrados na utilização de jogos em sala de aula seriam decorrentes de uma má formação dos professores. No entanto, ao final nos deparamos com mais questões. Nesta pesquisa foi possível perceber que faltou experimentação na formação, mas existiu a parte teórica. E que, apesar de terem tido essa nova leitura da educação em que o professor deve ser capaz de reformular sua pratica através de estratégias diferenciadas, as professoras entrevistadas acabaram por conhecer e estudar os documentos oficiais $\mathrm{e}$ bibliografias da área somente durante a graduação. Para elas existe uma ampliação das habilidades e competências que o professor adquiriu durante sua formação na sua experiência em sala de aula. Este fato nos fez pensar que a formação não pode ser encarada como a única vilã, pois faltou experimentar na faculdade, mas também faltou empenho das professoras pesquisadas na superação de suas capacidades. De todo modo, ficou claro que as professoras entrevistadas conseguem, através do jogo, envolver seus alunos, criar possibilidades de desenvolvimento de estratégias, cálculo mental e estimativa características do aprimoramento do raciocínio lógico essenciais na Matemática.

A dificuldade de encontrar as razões pelas quais os jogos nesta pesquisa não tiveram caráter investigativo nos faz concordar com Kamii (1995), para quem o uso dos jogos pelos professores é uma arte que requer reflexão e experimentação para que possa potencializar o ensino.

Além disso, concluímos que construir cenários investigativos é muito difícil. Fazer Matemática a partir de novas perspectivas requer a superação de nossas capacidades para que possamos permitir novas experiências de aprendizagem. Como aponta Guérios (2002):

\begin{abstract}
A perspectiva inovadora reside, na verdade, na postura diferenciada que professores e alunos passam a ter em relação ao conhecimento. Uma postura interrogativa, questionadora, investigativa, exploratória e de produção e negociação de sentidos perante o saber. Ou seja, uma postura em que alunos e professores se constituem, ambos, em sujeitos críticos do aprender e do conhecer. (GUÉRIOS, 2002 apud FREITAS, 2008, p. 78)
\end{abstract}

A pesquisa nos permitiu perceber que ser professor é muito mais complexo do que se imagina. Podemos não estar totalmente preparados para fazer tudo o que desejamos, mas cabe a nós buscarmos cada vez mais uma melhor qualidade de ensino onde todos, professores e alunos, possamos ter acesso ao saber.

Ao desenvolver o trabalho percebemos que não chegaríamos a uma 
única resposta que concluiria a questão que desencadeou a pesquisa e constatamos o surgimento de inquietações e questionamentos que poderão servir para futuros trabalhos. Inquietações tais como: será que o conhecimento matemático do professor dá segurança para que ele possa trabalhar com metodologias diferenciadas no ensino da Matemática?

Ao realizar este trabalho tivemos oportunidade de conviver em grupo desenvolvendo um tipo de pesquisa científica, aprendendo uma maneira de buscar entender alguns questionamentos surgidos através de experiências vivenciadas por nós. Aprendemos com isso a relacionar dados reais com a teoria estudada. Além disso, pudemos crescer como profissionais da educação aprendendo como é possível potencializar o ensino de Matemática através da utilização de jogos que não devem ser apenas para divertir, mas precisamos extrair dessa atividade conteúdo suficiente para gerar um conhecimento, fazendo os alunos pensarem e se motivarem nas aulas de Matemática.

\section{REFERENCIAS BIBLIOGRAFICAS}

[1] BRASIL, Ministério da Educação e do Desporto.Secretaria de Educação Fundamental. Parâmetros Curriculares Nacionais: terceiro e quarto ciclos do ensino fundamental: matemática $\left(5^{\mathrm{a}}\right.$ a $8^{\mathrm{a}}$ séries). Brasília, 1998.

[2] KAMII, Constance. Desvendando a aritmética - implicações da Teoria de Piaget/ Constance Kamii e Sally J. Livingston; tradução Marta Rabioglio e Camilo F. Ghorayeb. Campinas, SP; Papirus, 1995.

[3] MACEDO, Lino; PETTY, Ana Lúcia Sícoli; PASSOS, Norimar Christe. Os jogos e o lúdico na aprendizagem escolar. Porto Alegre; Artmed, 2005.

[4] BORIN, Julia. J ogos e resolução de problemas: Uma estratégia para as aulas de matemática. $3^{\text {a }}$ ed., São Paulo; Caem, 1998.

[5] SKOVSMOSE,Olé. Cenários para investigação. In: Bolema, no 14, p 66 a 91,2000:

[6] PERRENOUD, Philippe. Construindo Competências. In: Revista Nova Escola, Edição on-line, n. ${ }^{\circ} 135$, Setembro 2000. http://revistaescola.abril.com.br/ed_anterio res/0135.shtml. Acesso em 15 de Set. de 2008.

[7] FREITAS, Luciana Maria Tenuta de. 0 desafio de construir espaços de formação profissional para professores de Matemática envolvendo egressos de um curso de licenciatura. Dissertação (Mestrado em Ensino de Matemática) PUC Minas. Belo Horizonte, MG. Orientadora: Eliane Scheid Gazire, 2008, 146p. 